\title{
Creating Contexts for Adult Motivation for Foreign Language
Learning and Acquisition for Foreign Language
Learning and Acquisition
}

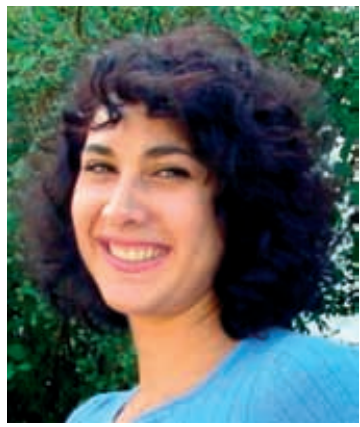

Marina Karapetyan

A ll teachers ask themselves: "What shall I do to help my students get started?", "What will help them to sustain interest in what they learn?" In search of "What?" we arrive at the question of motivation. It is common knowledge that two people of the same ability, age and gender will achieve different results in working on the same task if they have different degrees of motivation. Motivated students are willing to learn by listening, asking questions, reacting, participating. They enjoy being able to contribute to the learning process and class work. They are "more psychologically open to the learning material and enhance information processing” (Wlodkowsky, 1993).

Motivation is a reason or a group of reasons, for which people do things. In Applied Linguistics it is referred to as one of the variables affecting second/foreign language acquisition. Along with variables of self-esteem and the level of anxiety, it "lowers the affective filter ${ }^{1}$ ", which does not allow the comprehensible input to "enter the language acquisition devise” (Krashen, 1981). Thus, motivation secures productive learning and acquisition.

This research considers the problem of foreign language learning/acquisition by young adults (17-20 years old). In order to understand how to motivate adults, and why they need to be motivated, it is necessary to see how they learn a foreign language.

First, they start learning a language having certain experience and established way of thinking, which gives them advantage over younger learners. Second, they are conscious of learning a new language and have their preferred learning styles, which must be considered in the choice of teaching materials and methods. Third, they have formed native language skills, which allow them to produce a foreign language using the conscious grammar to adjust to target language structures. Fourth, adults are better communicators (Scarcella and Higa in press as cited in Krashen, 1981), which considerably expands learning opportunities. Also, they may have numerous cognitive demands for using a foreign language, such as filling out tax forms, job applications, writing cover letters, corresponding and solving problems through e-mail, etc. Thus, what they learn can be directly applied to their lives (Escamilla, 2002).

At the same time, adults can face difficulties. For instance, sometimes native 
language literacy hinders the development of new language skills and abilities. Adults are conservative learners, and it can be a challenging task to incline them to using new sounds, language functions, or multiple verb tenses, which are different from what they
have used before.

Another unfavorable quality of adults is that they are poorer acquirers than children. Their language intuition is formed slowly, and they usually do not perceive the comprehensible input subconsciously because they focus on the form rather than meaning. Adult leamers analyze the input from grammatical, logical and philosophical viewpoints, and are over-concerned about making rapid progress in speaking. They lose intrinsic motivation to continue learning if no visible results appear soon.

When teaching adult learners, we must make every effort to eliminate their flaws because, according to the affective theory of processing and learning a foreign language, all the above mentioned psychological and mental conditions can hinder the work of the brain by blocking it from assimilating new information. Surprising as it can be, adults
do need encouragement and motivation.

Wlodkowsky's review of psychological research (1993) decomposes the notion of 'motivation' into at least 6 constituents: attitude, need, stimulation, affect, competence, and reinforcement. I intend to demonstrate below how the affective filter may be reduced by integrating them into the process of teaching through games.

Attitude is generally defined as a condition of mind or soul which affects people's feelings towards other people, facts or phenomena. Negative feelings impair memory functions and distract from focusing on the target language. The complete notion of a positive attitude implies that "wo want adults to like and respect us and our subject matter, and feel confident as learners who realistically believe they can succeed in the learning task at hand" (Wlodkowsky, p. 73). That is where the power of ganes lies: they create an atmosphere of trust and diminish frustration. Learners do not feel any threat of failure: gaming results are not assessed and mistakes are not viewed as enemies. They do not focus on grammatical forms, but on the content of messages. Games are played for pleasure, while learning occu's subconsciously. They build a liking towards the instructor and the target language as they ensure interesting lessons with a wide variety of activities, in which learners can display their own projects and talents. Sharing skills and abilities with one's classmates provides efficient feedback as long as different adults use distinct approaches and techniques to solve similar problems. At the same time, learners get positively reinforced through approval and praise.

Need is a major element of motivation that determines people's behaviour, with the need for self-filfilment and the need to understand as important social needs to be satisfied. On the other hand, it is want that makes people do particular things. As a matter of fact, need and want are comparable to extrinsic and intrinsic factors of molivation, respectively. People may need to learn English to pass an examination, or to go on a business trip, or for personal enrichment, for instance. They will want to learn it, however, if the lesson is interesting, 'tailored' to their particular needs and applicable to their lives. Learning what they want to learn is a real enjoyment. They will be able to achieve amazing results in a short time. Games contribute a great deal to awakening 
students' want to learn a foreign language and reinforce their need to learn it. Games simulate real-life discourse situations, allowing learners to practise language as a means of communication, as well as to demonstrate their initiative, creativity and independent thinking in real-world problem solving.

Stimulation creates feelings of enthusiasm and inspiration that influence learner behaviour positively. If the learning process or the teaching materials are not stimulating enough, learners' interest and attention will be lost irrespective of their attitude and need to learn the subject. Interest, in its turn, stimulates learners to greater learning activity, with attention helping to comprehend the inpul. Games stimulate thinking, imagination, spontameous talk and memorv. Even the least motivated leamers are urged to participate
in classroom activities.

According to Wlodkowsky, "to keep people stimulated means to keep them emotionally involved" (1993, p.142). Some psychologists claim that the emotional factor, termed affect, is the key to motivation. Effective learning is always emotional, especially when it concerns foreign language learning/acquisition. Games stimulate the expression of emotions in a plavful enviromment, where learners are psychologically fiee and natural displaying their temperanents and expressing true feelings on the subject matter. In this way they do not feel the pressure of learning as a must. If students are "amused, angered, intrigued or surprised, the content is clearly meaningful to them. Thus the meaning of the language they listen to, read, speak and write will be more vividly experienced and, therefore, better remembered"' (Wright, Betteridge, Buckby, p.1). And there is no place for anxiety as the atmosphere is relaxed and pleasant.

Awareness of competence is an intrinsic recessity of humans (While, 1959 as cited in Wlodkowsky, 1993). The realization of one's success or mastery lowers the anxiety level and builds self-confidence. In a gaming emiromment learners feel qualified to perform tasks and be adventurous with the target language. They are not only open to absorb the comprehensible input, but also able to express themselves, using the target language actively and creatively ${ }^{2}$.

Gaming techniques have been used since $60 \mathrm{~s}-70 \mathrm{~s}$, though they did not receive enough recognition at that time. Conservative and traditional language teaching methodology tended to underestimate the great pedagogical, educational and psychological aspects of game theory. Games were viewed as frivolous non-adult activities, while strenuous, lrumourless and steady-going tasks were considered to be more effective. At best, games were regarded as effective time-fillers, i.e. marginal techniques for a foreign language teaching programme. The primary goal of teaching to make a serious activity more appealing and challenging - was neglected. Games have only gained currency in the last three decades mostly due to thorough research by Lee, 1979; Jones. 1982 and, Ladousse 1987 as cited in Tompkins (no date) and others, where the authors bring persuasive arguments in favour of games not only as energizers, but also as excellent language practice means and invaluable sources of motivation and enthusiastic learner behaviour. The application of games in a foreign language classroom is particularly useful as students are acquiring an 'alien' language in the absence of authentic linguistic and cultural surroundings. 
Through games students acquire language competence by listening and understanding messages, and not by learning rules. The words game and $p l a y$ themselves make them forget they are in a classroom, learning a foreign language. Their mind is shifted from the idea of 'learning' (which is very discouraging for lazy-type young adults) to the idea of 'playing', and is concentrated on the rules of the game, collaboration, competition, challenge and interaction. Games require learners' active involvement, thus making the process learner-centred. Students become more dynamic and strenuous and ready to contribute their own views, thoughts, solutions and ingenuity.

As we see, language games are motivators. However, they are also beneficial for other important reasons. In particular, they integrate different language skills, develop numerous life skills, promote class cohesion and enhance interpersonal communication.

I originally started using gaunes in my practice as mere warm-ups and energizers. Soon, however, seeing my students' progress and enthusiasm. I also introduced them as encouragement for well-done homework or active participation. Now I use games to introduce, reinforce and revise the grammatical material, vocabulary, spelling rules, as well as to assist my students in writing and reading, to improve listening skills and for many other purposes.

Truly. "a language is learnt by using it in situations and communicatively" (Lee, 1997, p.1). In this sense, introduction of gaming practices in teaching foreign languages becomes an extreme necessity especially if we take into account that we acquired out mother tongue also through playing and language games. Games are the reflection of the surrounding world. In other words, they are models of genuine communication based on real life patterns.

\section{Final considerations}

In conclusion, motivation may be viewed as the key factor influenced by two other affective variables: anxiety and self-esteem, the absence of which may result in the loss of motivation to learn. On the other hand, awareness of positive results, success, teacher's approval and a pleasant relaxed atmosphere may serve as prerequisites for motivation. In addition, motivation not only facilitates learners' active behaviour during the lesson, but also provides its continuity.

1 also suggest an integrated approach to teaching young adults, motivating them and reinforcing different language skills at the same time. We see that games can be not only valuable sources of motivation for a foreign language class but also relevant means of language use in authentic contexts. Games lay the path to loose and 'subconscious' communication and significantly facilitate the complex process of foreign language learning/acquisition.

\section{References:}

1. Cummins, J. Knowledge, Power, and Identity in Teaching ESL. // Educating Second Language Children. / Genesee, F. (ed.). Cambridge, Cambridge University Press, 1994.

2. Dubin, F. \& Olshtain, E. Facilitating Language Leaming. A Guidebook for the ESL/EFL Teacher. New York, McGraw-Hill International Book Company, 1977. 
3. Escamilla, K. Lecture Notes. The University of Colorado, Boulder, CO, 2002.

4. Krashen, S. Bilingual Education and Second Language Acquisition Theory. // Schooling and Language Minority Children: A Theoretical Framework. Los Angeles, Dissemination and Assessment Center, California State University, 1981.

5. Lee, W.R. Language Teaching Games and Contests. Hong Kong, Oxford University Press, 1997.

6. Wlodkowsky, R. Enhancing Adult Motivation to Learn. San Francisco, Jossey-Bass Publishers, 1993.

7. Tompkins, Patricia K. (No date). Role Playing/Simulation. http://iteslj.org/Techniques/Tompkins-RolePlaying.html

8. Wright, A., Betteruge D. \& Buckby, M. (No date). Games for Language Learning. http://www teflgames.com/why/html

\section{Notes:}

1 In the second/foreign langnage acquisition theory, the affective filter refers to extralinguistic conditions that hamper the process of leaming by blocking the perception of information by the brain.

2 The process is termed "comprehensible output" by Swain (1986 as cited in Cumnins, 1994).

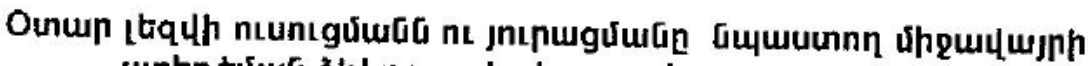

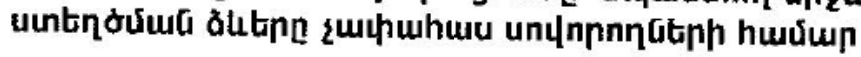

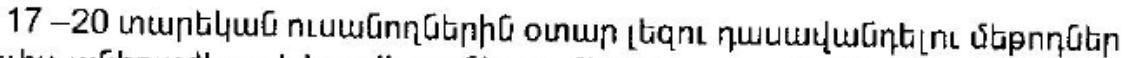

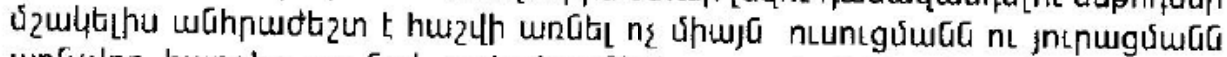

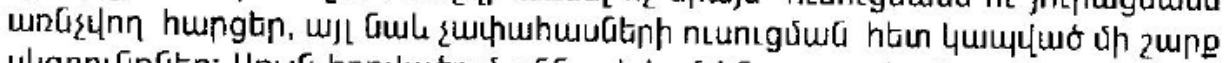

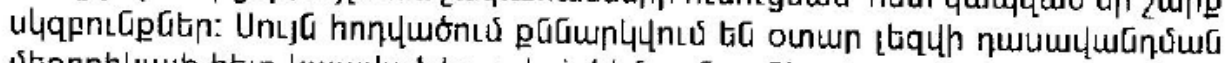

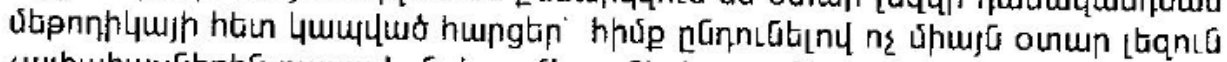

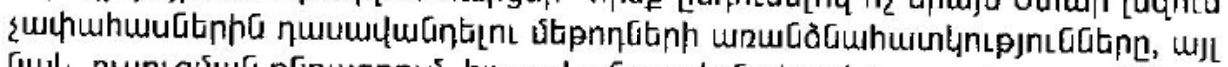

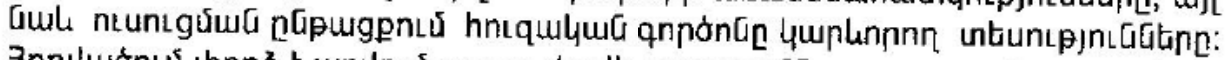

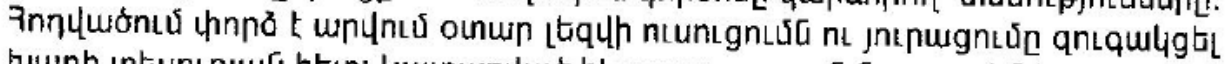

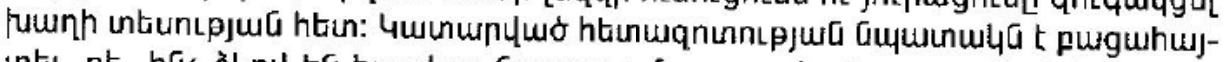

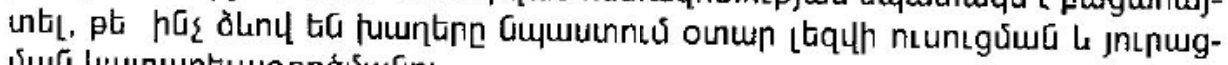

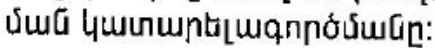

